\title{
www.czasopisma.pan.pl \\ The Effect of Carbides Orientation in NC11 Steel on Scratch Susceptibility of Die Inserts Used to Press Stampings for Refractory Shapes
}

\author{
A.W. Orłowicz ${ }^{\text {a*}}$, M. Mróz ${ }^{\text {a }}$, M. Tupaj ${ }^{\text {a }}$, A. Trytek ${ }^{\text {a }}$, B. Kupiec ${ }^{\text {a }}$, M. Korzeniowski a ${ }^{\text {, }}$ \\ K. Sondej ${ }^{\text {b }}$, L. Kozak ${ }^{b}$ \\ ${ }^{a}$ Rzeszow University of Technology, Al. Powstańców Warszawy 12, 35-959 Rzeszów, Poland \\ ${ }^{\mathrm{b}}$ ZM Service Sp. z o.o., ul. Przemysłowa 1, 39-100 Ropczyce, Poland \\ *Corresponding author. E-mail address: aworlow@prz.edu.pl
}

Received 31.03.2016; accepted in revised form 22.04.2016

\begin{abstract}
NC11 steel, in view of the specificity of its manufacturing process, is characterised with band-like orientation of carbides. Depending on the direction of cutting the material for the inserts out of commercially available steel products, carbide bands can be oriented in parallel or perpendicularly to the direction in which aggregate grains move in the process of pressing stampings. It has been found that in case of scratches made in direction perpendicular to carbide bands, depth of the scratches is less than this observed when scratches are made in direction coinciding with prevailing orientation of carbide precipitates.
\end{abstract}

Keywords: NC11 steel, Die insert, Scratch susceptibility

\section{Introduction}

Materials used for fabrication of machine parts which are expected to show high resistance to abrasive wear are typically characterised with microstructures rich in precipitates of hard carbide phases. This group of materials includes, among others, the so-called tool steels.

Replaceable inserts for metal dies used to press-mould stampings from refractory materials in Zakłady Magnezytowe Ropczyce S.A. [Ropczyce Magnesite Works plc.] must be characterised with high resistance to abrasive wear in dry friction conditions in view of high hardness of the pressed aggregate, reaching as high values as $1842 \mathrm{HV} 0.5$ in case of fused alumina. The inserts are made of NC11 cold-work tool steel, thermally treated (hardening + tempering) up to 60-61 HRC.

NC11 steel is characterised with band-like orientation of carbides. In view of service properties of die inserts made of the steel it is an interesting issue to determine to what extent the resistance to abrasive wear is affected by orientation of carbides with respect to direction of motion of hard particles contained in the mass used to mould stampings for precast refractory shapes.

$\mathrm{NC} 11$ steel can be described as an in situ composite with hard carbide precipitates embedded in significantly softer matrix. Similar structure characterises the chrome cast iron, high resistance of which to abrasive wear is a result of high volumic share of diversely oriented carbide precipitates.

In paper [1], concerning chromium cast iron containing $24.5 \%$ $\mathrm{Cr}$, it has been found that the abrasive wear resistance of the material in which carbide precipitates were oriented with their long axes oriented perpendicularly to the surface of friction was higher than this corresponding to parallel alignment of the precipitates with respect to the contact surface. In the latter case, the resistance to abrasive wear was higher when long axes of carbide precipitates were essentially perpendicular to direction of abrasion and lower when their predominant orientation was parallel to the abrasion path.

Authors of the paper [2] examined the effect of orientation of carbide precipitates on resistance to abrasive wear characterising chromium cast iron containing $16.2 \% \mathrm{Cr}$ with the 
use of the dry sand rubber/wheel abrasion test, the low-stress three-body abrasion test, and the erosion test. They have found that when the long axes of carbide precipitates were oriented parallel to the friction surface, the material turned out to be more resistant to abrasive wear when tested by means of all of the above-mentioned methods. In case of the erosion test, the authors noted that when the long axes of carbide precipitates were parallel to the friction surface, higher resistance to abrasive wear was observed for the case of abradant particles displacing in the direction perpendicular to long axes and lower when abrasion proceeded parallel to long axes of the precipitates. However, in case of the three-body abrasion test, no effect of carbide precipitate orientations on abrasive wear was observed.

According to authors of paper [3], the cast iron with austenite matrix presented higher wear resistance than the iron with martensitic matrix for abrasives with grain size of $66 \mu \mathrm{m}$ and $93 \mu \mathrm{m}$. For finer abrasives, more penetration and plastic deformation on austenitic matrices was observed. Iron with martensitic matrix produced more microcutting, increasing the wear rate of the material.

The presented review of literature of the subject shows that the problem of abrasive wear of materials containing carbide precipitates in austenitic, martensitic, or austenitic-martensitic matrix is a complex issue in which both orientation of carbide precipitate bands and matrix properties must be taken into account.

The present paper deals with abrasive wear resistance of die inserts used to manufacture press stampings from refractory materials. The stampings contain particles of fused alumina, characterised with hardness 9 in the 10-level Mohs scale of mineral hardness, i.e. being the hardest material second only to diamond. This is the rationale behind carrying out the resistance tests by means of the scratch technique with the use of diamond indenter.

\section{Research methodology}

Industrial practice indicates that die inserts made of NC11 steel with the same nominal hardness show different abrasive wear resistance

In order to acquire knowledge about abrasive wear of steel inserts for dies used to fabricate stampings from the raw refractory mass with matrix containing grains of fused alumina (hardness 9 in Mohs' scale), a die insert was prepared that was then used to fabricate a single stamping as well as another insert used further to produce 3600 stampings.

On these two inserts, value of the parameter $S_{\mathrm{t}}$ characterising geometrical structure of surface was assessed. The parameter reflects the difference between elevation of raises and depressions of the tested surface.

Examination of the geometrical structure of insert surfaces was performed with the use of HOMMEL ETAMIC roughness measuring system (JENOPTIK), using: levelled profile, ISO 11562 filter, and TKU300 measuring tip moving at speed $V_{\mathrm{t}}=$ $0.5 \mathrm{~mm} / \mathrm{s}$.

In order to acquire knowledge on different phenomena contributing to wear of die inserts, plates with dimensions $20 \mathrm{~mm}$ $\times 20 \mathrm{~mm} \times 5 \mathrm{~mm}$ were cut out from used inserts for metallographic examination, quantitative analysis of microstructure, and scratch tests.

The metallographic examination and the quantitative microanalysis of chemistry was performed with the use of VEGA scanning electron microscope (TESCAN) equipped with $\mathrm{x}$-act adapter for chemistry microanalysis (Oxford Instruments).

Scratch tests were performed with the use of Revetest RST macro scratch tester (CMS Instruments). In the scratch tests, a diamond Rockwell-type indenter C-281 was used with tip radius $200 \mu \mathrm{m}$ and apex angle $120^{\circ}$. The adopted load force value was 5 $\mathrm{N}$ and the scratch length $2 \mathrm{~mm}$. In the scratch test, values of the following quantities were determined: the friction force $F_{\mathrm{t}}$, the friction coefficient $\mu(F C)$, the acoustic emission index $A E$, and the penetration depth $P_{\mathrm{d}}$.

\section{Results of the research}

A view of surface of an experimental insert after press moulding a single stamping together with corresponding value of the height parameter $S_{\mathrm{t}}$ is shown in Fig. 1.

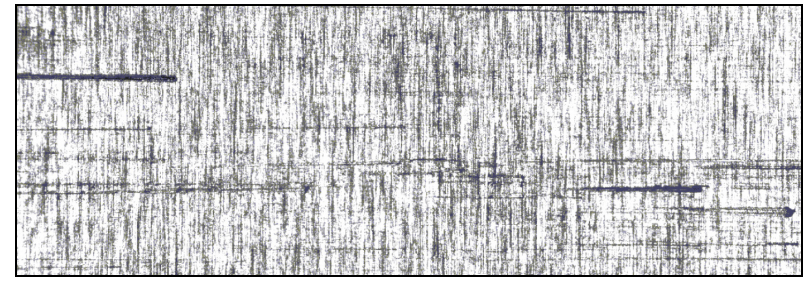

$$
S_{\mathrm{t}}=1.81 \mu \mathrm{n}
$$

Fig. 1. Surface of experimental insert after press moulding a single stamping and the corresponding $S_{\mathrm{t}}$ value

The obtained results indicate that there are isolated scratches on the tested surface.

A view of surface of an experimental insert after press moulding 3600 stampings together with corresponding value of the height parameter $S_{\mathrm{t}}$ is shown in Fig. 2.

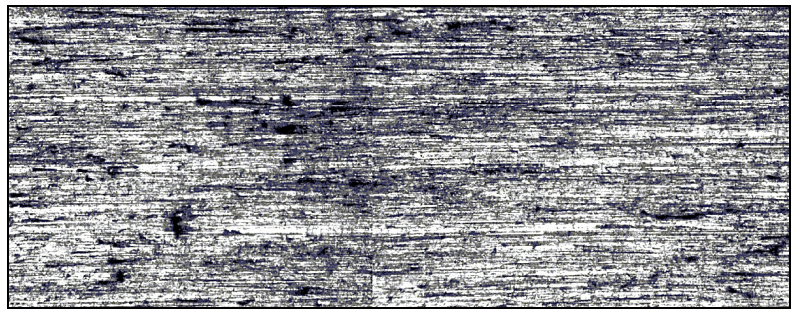

$$
S_{\mathrm{t}}=22.96 \mu \mathrm{m}
$$

Fig. 2. Surface of experimental insert after press moulding 3600 stampings and the corresponding $S_{\mathrm{t}}$ value

The obtained results indicate that the value of parameter $S_{\mathrm{t}}$ has increased significantly. This suggests existence of a process of deepening the scratches consisting in that edges of aggregate particles are more easily guided along the existing depressions.

Fig. 3 shows an example microstructure of $\mathrm{NC} 11$ steel and results of microanalysis of the chemistry of the carbides. 


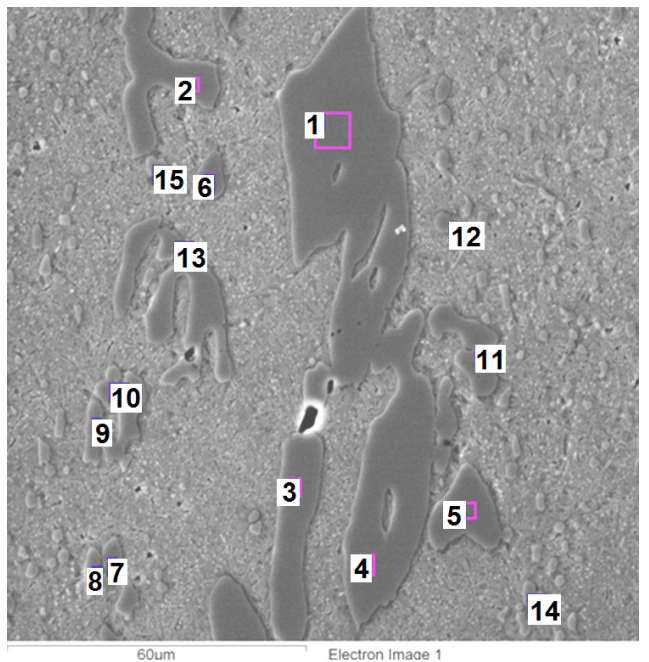

\begin{tabular}{cccc}
\hline \multirow{2}{*}{ Point } & \multicolumn{3}{c}{ Content, \%wt.* } \\
\cline { 2 - 4 } & $\mathrm{Cr}$ & $\mathrm{Mn}$ & $\mathrm{Fe}$ \\
\hline 1 & 44.83 & 0.22 & 45.02 \\
2 & 37.16 & 0.26 & 54.17 \\
3 & 8.10 & 0.20 & 87.35 \\
4 & 9.99 & 0.29 & 87.83 \\
5 & 16.16 & 0.23 & 82.27 \\
6 & 8.78 & 0.23 & 86.77 \\
7 & 7.05 & 0.15 & 88.57 \\
8 & 7.82 & 0.16 & 86.80 \\
9 & 32.49 & 0.22 & 57.80 \\
10 & 7.30 & 0.21 & 88.24 \\
11 & 8.70 & 0.19 & 87.81 \\
12 & 8.43 & 0.21 & 87.83 \\
13 & 42.89 & 0.25 & 47.26 \\
14 & 9.36 & 0.23 & 86.80 \\
15 & 9.96 & 0.19 & 84.13 \\
\hline * carbon and other elements to balance
\end{tabular}

* carbon and other elements to balance

Fig. 3. Results of single-point quantitative microanalysis of $\mathrm{NC} 11$ steel chemistry

The obtained results show that the carbides include chromium in the quantity from about $7 \%$ to $44 \% \mathrm{Cr}$ and iron from about $45 \%$ to $88 \% \mathrm{Fe}$, as well as manganese from about $0.15 \%$ to $0.29 \% \mathrm{Mn}$. The carbides differ by shapes and lengths of precipitates. The length of fine carbides is $2 \mu \mathrm{m}$, while some precipitates can be as long as $120 \mu \mathrm{m}$.

Figs. 4 and 5 show results of the scratch resistance test with diamond indenter guided in direction parallel and perpendicular to carbide precipitate bands.

The obtained results indicate that the depth of scratch made in direction perpendicular to carbide bands $\left(h_{\mathrm{av}}=1.37 \mu \mathrm{m}\right)$ is significantly larger than the depth of scratches occurring in direction parallel to carbide bands $\left(h_{\mathrm{av}}=0.96 \mu \mathrm{m}\right)$.

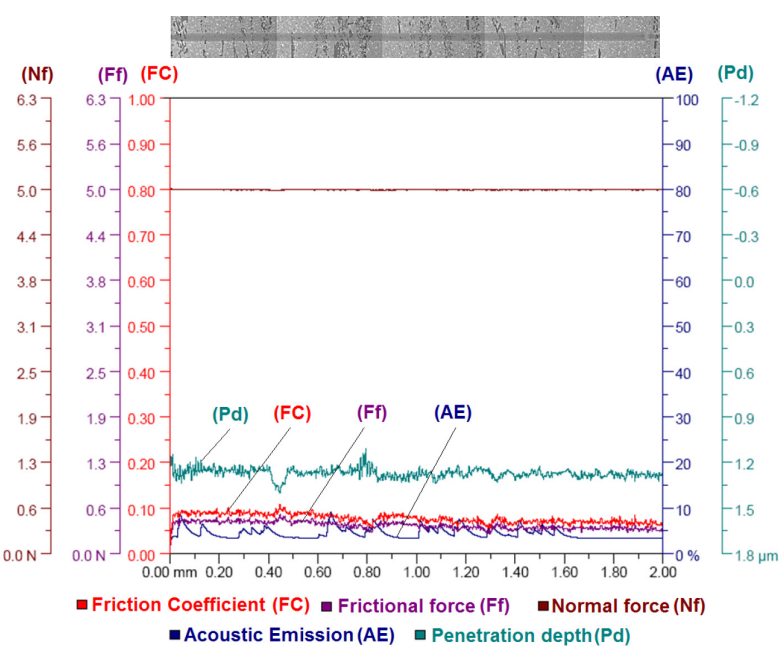

Fig. 4. Results of NC11 steel scratch tests in direction parallel to carbide bands

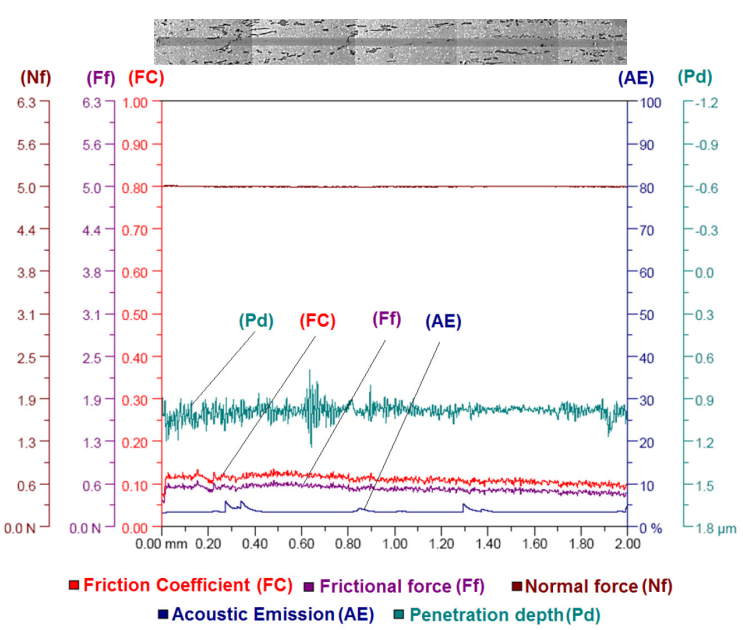

Fig. 5. Results of NC11 steel scratch tests in direction perpendicular to carbide bands

The obtained results are consistent with results of paper [4] in which the author suggests that orientation of carbides has an effect on resistance of chromium cast iron to abrasive wear.

Peaks on the acoustic emission waveforms are an evidence of degradation processes occurring in the material at the moment of the indenter getting onto carbides. The peaks can represent a response of the material to the process of plunging carbides into the matrix, an effect of scraping hard carbides by the indenter's diamond tip, or, in extreme cases, the noise generated by cracking carbides.

Fig. 6 is a view of scratches made with diamond indenter and cracked carbide precipitates.

The obtained results indicate that carbides were not subject to deformation, observed by authors of [4] in case of scratch-testing chromium cast iron surface with diamond indenter. On the other hand, likewise in the experiment described in the above-quoted paper, carbide cracks were observed in areas adjacent to scratch edges. 
(a)

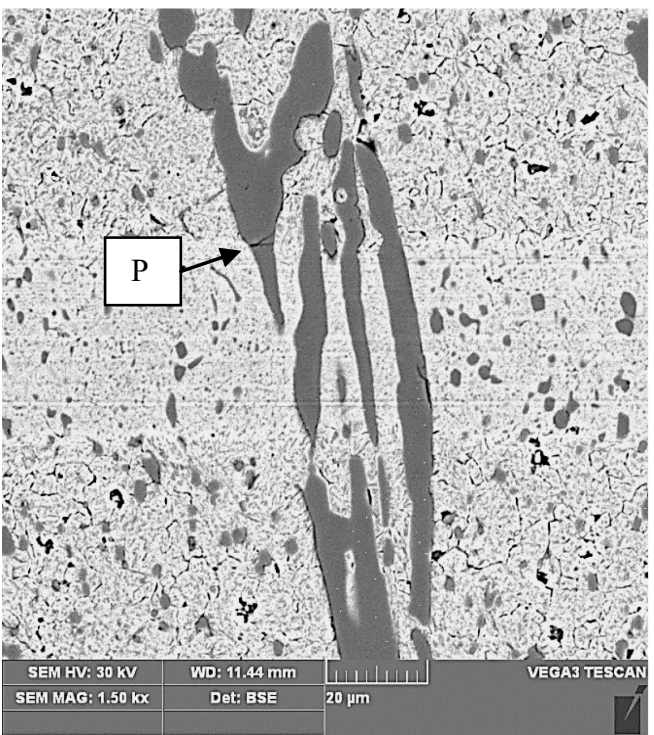

(b)

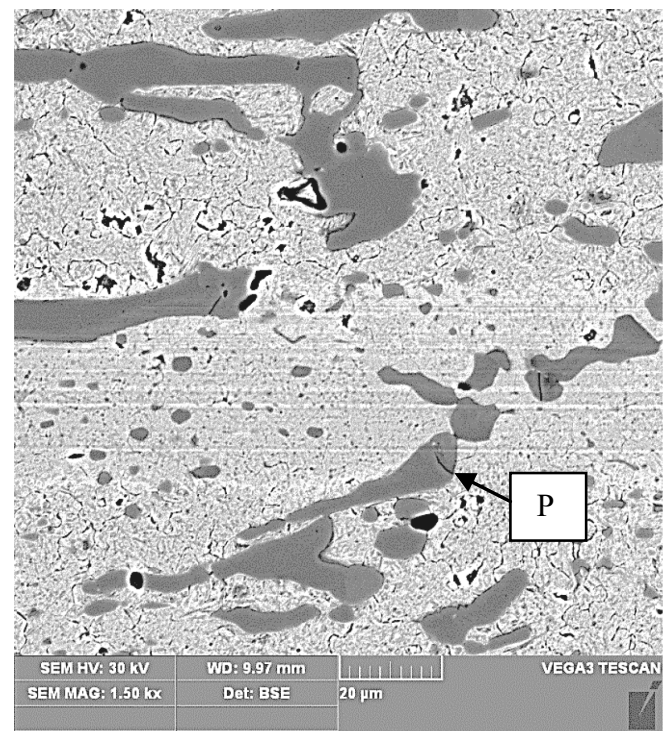

Fig. 6. An example view of scratches made with a diamond indenter in direction (a) perpendicular and (b) parallel to orientation of carbides. P - broken carbides

\section{Conclusions}

Microstructure of NC11 steel is characterised with occurrence of carbides rich in chromium and iron, containing also manganese.

Band-like orientation of carbides in NC11 steel has an effect of the material's resistance to abrasive wear.

Scratches made in direction perpendicular to orientation of carbide bands are shallower compared to those made in direction parallel to prevailing orientation of carbides.

Material scratching triggers the stress level high enough to create conditions favourable to carbide cracking.

No deformations of carbide precipitates were found in the scratch areas.

\section{Acknowledgement}

The study presented in this paper was carried out in the framework of project entitled INNOVATIVE TECHNOLOGICAL PROCESS OF MANUFACTURING MOULDS FOR PRODUCTION OF REFRACTORY MATERIALS co-funded from Operational Programme Innovative Economy, Measure 1.44.1 Support for goal-oriented projects and support for implementation of results of R\&D works.

\section{References}

[1] Dŏgan O.N., Hawk J.A. (1995). Effect of carbide orientation on abrasion of high $\mathrm{Cr}$ white cast iron. Wear, 89, 136-142. DOI: 10.1016/0043-1648(95)06682-9.

[2] Junyi S., Yuding J (1987). Wear of Materials. ASME, New York, 661-671.

[3] Cortonado J.J., Sinatora A (2009). Abrasive wear study of white cast iron with different solidification rates. Wear, 267, 2116-2121.

[4] Cortonado J.J. (2011). Effect of $(\mathrm{Fe}, \mathrm{Cr})_{7} \mathrm{C}_{3}$ carbide orientation on abrasion wear resistance and fracture toughness. Wear, 270, 287-293. DOI10.1016/j.wear.2010.10.070. 